\title{
A lua vermelha de Kapoor
}

\author{
Alexandra Moreira da Silva \\ Titulo: Tambores na noite (Trommeln in der Nacht, 1922/1953). Autor: Bertolt Brecht. Tradução: Claudia J. Fischer. Encenação e \\ cenografia: Nuno Carinhas. Figurinos: Bernardo Monteiro. Desenho de luz: Rui Simão. Desenho de som: Joel Azevedo. Preparação \\ vocal e elocução: João Henriques. Colaboração musical: António Sérgio. Interpretação: Emília Silvestre, Fernando Moreira, Joana \\ Manuel, João Castro, Jorge Mota, José Eduardo Silva, Luís Araújo, Marta Freitas, Paulo Freixinho, Pedro Almendra, Pedro Frias, Sara \\ Carinhas e Pedro Jorge Ribeiro. Produção: Teatro Nacional S. João. Local e data de estreia: TNSJ, Porto, 20 de Março de 2009.
}

Aquilo que permaneceu muito tempo sem alteração parece, de facto, inalterável.

A voz gravada que nos recorda que o espectáculo vai começar não é exactamente aquela que nos habituamos a ouvir no Teatro Nacional São João (ela voltará mais tarde, para anunciar os tumultos nos bairros dos jornais). E o rufar marcial dos tambores nos camarotes laterais só com algum esforço nos faria pensar de imediato nas familiares pancadas de Molière. No entanto, é desta forma "estranha" que o espectador de Tambores na noite é recebido no muito orgânico espaço deste teatro, até que a cortina de cena, elemento teatral por excelência que será frequentemente explorado nesta encenação, se abra, finalmente.

Desenganem-se aqueles que estão neste momento a pensar que estes dois momentos iniciais nos "distanciam" do objecto teatral a que vamos assistir. Bem pelo contrário, tal como os objectos cénicos, os efeitos de luz, os figurinos ou o próprio jogo dos actores, os sons e a música pontuarão a narrativa pondo em evidência o gestus social da obra, ou seja, "a expressão exterior, material, dos conflitos de sociedade" na apresentação já não de um "teatro do mundo" (Sarrazac 2002: 217), mas muito mais de um "texto do mundo", necessariamente fragmentado, que apela à exigente combinação entre o fundo e a forma, entre o intelecto e a emoção, entre uma dramaturgia do "intimo" e uma dramaturgia do "político". Não fora Brecht esse imenso "poeta da inteligência crítica" (Guénoun 2009: 57) e tudo seria mais simples.

Nuno Carinhas, que assina esta encenação (a primeira enquanto director artístico do Teatro Nacional São João) e a cenografia, não hesita em afirmar que o que mais the interessou nesta peça foi precisamente a dualidade latente ao longo de todo o texto "entre o pequeno drama individual e a mundividência da movimentação de massas, ambos caóticos" (Carinhas 2009: 10). E é precisamente o tratamento desse caos que atrai o encenador, a possibilidade de lhe dar uma forma. Sendo Tambores na noite uma obra do jovem Brecht, admirador de Rimbaud, de Villon e de Wedekind, o texto apresenta-se como um laboratório de formas dramáticas e teatrais onde é bem visivel a crítica ao teatro expressionista, mas onde começa já a germinar a teoria do teatro épico. 0 grande interesse deste espectáculo parece-me residir precisamente no facto de não existir, por parte do encenador e do colectivo criativo, uma verdadeira preocupação em mostrar elementos expressionistas ou épicos. Mais do que situar a obra brechtiana "contra e/ou a favor de" uma qualquer corrente literária ou artística, procura-se encontrar um conjunto de "sintonias" com o universo poético do autor alemão. Existe não só um claro desejo de pôr em evidência o carácter profundamente artesanal e rapsódico do trabalho dramatúrgico e teatral que a obra de Brecht pressupõe, como também uma vontade explicita de realçar 0 inconformismo e a experimentação de uma escrita que nunca se apresenta fechada ou definitiva. (Como é sabido, Brecht regressa continuamente aos textos que escreve; a primeira versão de Tambores na noite é de 1919, seguese uma segunda versão em 1922 e finalmente a última em 1953.) De facto, esta ideia de um trabalho "artesanal" surge de forma inequivoca logo nas primeiras obras. Em 1926, Brecht sugere a Marieluise Fleisser (que assistira à estreia de Tambores na noite, em Munique, em 1922), a propósito da sua peça Pioneiros em Ingolstadt, que a escrita deverá ser um trabalho de bricolage, que o texto deve ser trabalhado como certos carros que vemos circular em Paris, carros fabricados artesanalmente a partir de peças que o construtor conseguiu reunir por mero acaso. "Mas veja como andam, veja como andam!", terá acrescentado o autor.

A ideia de "abertura" que caracteriza a obra brechtiana está presente ao longo de todo o espectáculo. Recuperando uma expressão do próprio encenador, poder-se-ia dizer que estamos perante "um espectáculo em sedimentações" onde a repetição/variação dos detalhes faz a diferença. A casa (burguesa) da familia Balicke surge em espaço aberto - opção dramatúrgica que permitirá um jogo permanente entre as noções de interior e de exterior, de espaço íntimo 
Tambores na noite,

de Bertolt Brecht, enc. Nuno Carinhas, TNSJ, 2009 (Paulo Freixinho

e Jorge Mota ),

fot. João Tuna.

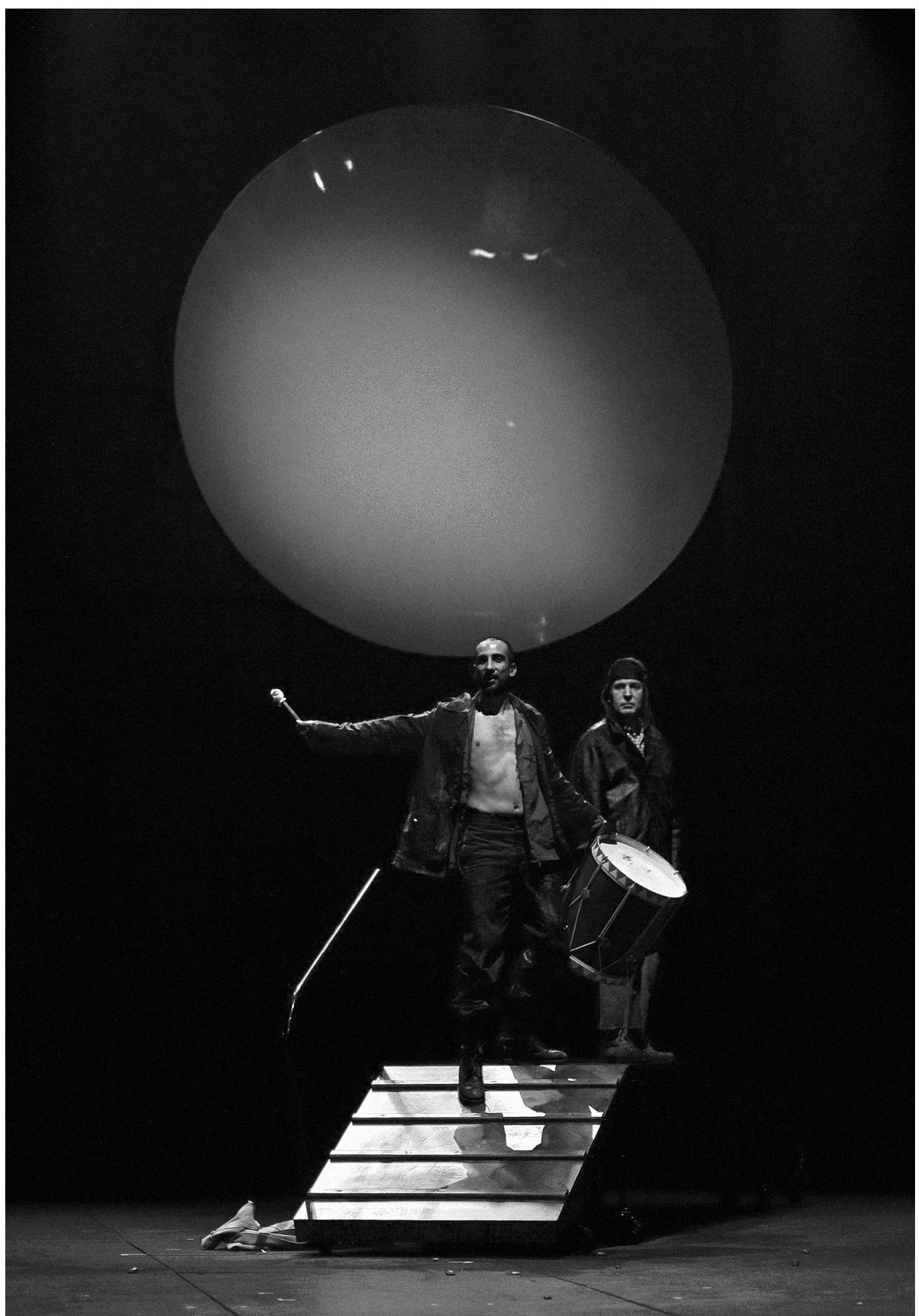

e de espaço público, um englobando o outro, evidenciando0 , contaminando o próprio espaço do teatro como espaço narrativo. Mas, na verdade, a concepção deste espaço assenta num subtil desenho de elementos cenográficos que, nunca perdendo de vista a perspectiva de abertura, proporciona aos actores um conjunto de elementos referenciais que lhes permite manter a intimidade: desde logo, as placas pretas alçadas/espelhos, o piano, as cadeiras, as mesas, a toalha branca que cobre a mesa de três metros da sala de jantar da familia Balicke, a própria cortina de cena que permite que os momentos de maior lirismo aconteçam precisamente à boca de cena, a lua "tão vermelha lá fora".

A ideia de "dualidade" é frequentemente incorporada nesses elementos, como se cada um constituisse um prolongamento da própria fábula. Isto é visivel nas diferentes funções que vão exercendo - as placas pretas alçadas serão espelhos no Bar Picadilly, onde cada personagem se poderá confrontar consigo própria e consequentemente com a realidade que prefere não olhar 

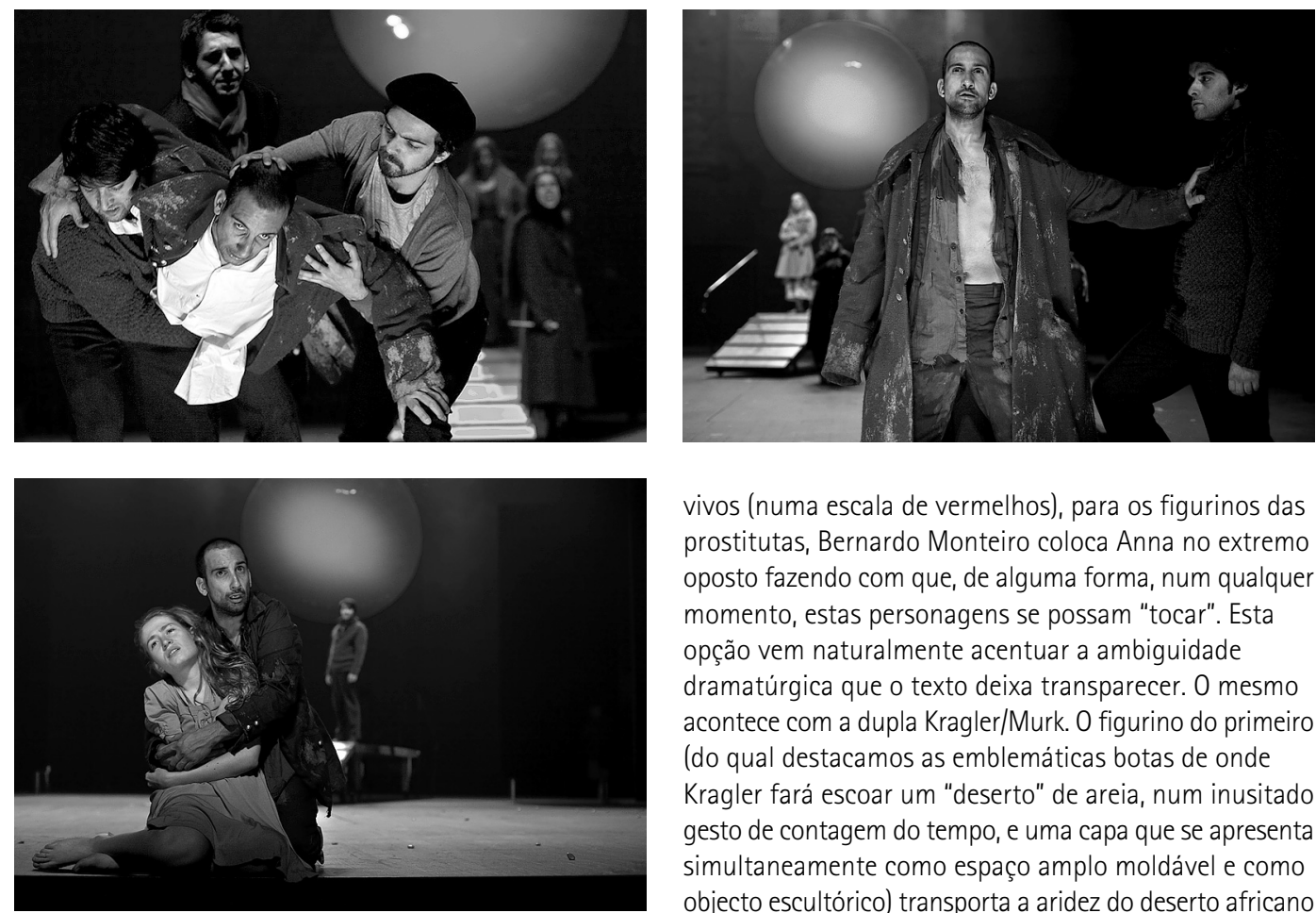

de frente; no quarto acto, o piano será também o bar da taberna, a música e o álcool onde se afogam as mágoas. A dualidade pode também estar presente no aspecto que os diferentes elementos assumem - a imensa lua vermelha tanto pode ser côncava como convexa - ou no seu valor simbólico - a toalha de mesa branca, usada por várias personagens, terá múltiplas funções sem nunca deixar de figurar, talvez mais ainda do que o próprio retrato, a presença espectral de Kragler da qual ninguém se consegue libertar verdadeiramente. Neste sentido, a cena não só utiliza como explora a sua própria linguagem, impondo as suas leis numa construção cénica que reclama e afirma permanentemente a sua teatralidade.

Os figurinos são, nas palavras de Patrice Pavis "uma cenografia à escala humana (...) que se desloca com o actor" (Pavis 1996: 160); é o espaço imediato que deve permitir a manifestação do corpo na totalidade dos seus movimentos, da sua gestualidade, do seu ritmo. Os figurinos de Bernardo Monteiro são - uma vez mais - um excelente exemplo de rigor e de criatividade na escolha e na conjugação de formas, de cores e de materiais.

Irrepreensiveis e indispensáveis para a leitura do gestus global do espectáculo, os figurinos permitem que as personagens surjam cromaticamente definidas: se os corpos ligeiramente dilatados do casal burguês vestem tons escuros, peles e chapéus que corroboram o tom farsesco adoptado pelos actores Emília Silvestre e Jorge Mota, Anna, a filha, surge com um surpreendente figurino em tons pastel que realça a sua palidez quase anémica e a sua fragilidade (Anna está grávida), como se, apesar da sua recente relação com Murk, todo o seu corpo manifestasse a presença espectral de Kragler. 0 figurino sublinha (sem condicionar) o trabalho da actriz Sara Carinhas que nos apresenta uma Anna invulgar, evocando por momentos personagens femininas de um universo dramático e teatral radicalmente diferente como são as maeterlinckianas Mélisande e Maleine. Ao optar por tons vivos (numa escala de vermelhos), para os figurinos das prostitutas, Bernardo Monteiro coloca Anna no extremo oposto fazendo com que, de alguma forma, num qualquer momento, estas personagens se possam "tocar". Esta opção vem naturalmente acentuar a ambiguidade dramatúrgica que o texto deixa transparecer. 0 mesmo acontece com a dupla Kragler/Murk. 0 figurino do primeiro (do qual destacamos as emblemáticas botas de onde Kragler fará escoar um "deserto" de areia, num inusitado gesto de contagem do tempo, e uma capa que se apresenta simultaneamente como espaço amplo moldável e como objecto escultórico) transporta a aridez do deserto africano (as pedras, a lama, a areia). É neste espaço que se movimenta um corpo também ele árido, sequioso, onde não vingarão sequer as ideias revolucionárias. Em contrapartida, Murk veste um figurino clássico (fato escuro, camisa branca) que convoca a ascensão social da personagem. Uma vez mais, as botas - desta vez cardadas - e o casaco protector, que simbolicamente Anna vestirá até ao momento em que volta para Kragler, serão os elementos mais emblemáticos e de imediata leitura dramatúrgica. No entanto, estas duas personagens diametralmente opostas acabam também por se "tocar": "porque um homem que é um homem consegue sempre safar-se" (Primeiro acto, "África") - das águas furtadas ou da guerra - e porque os sonhos de ambas se materializam na mais prosaica das imagens: "uma cama grande, branca e larga [...]!" (Quinto acto, "A cama").

Paulo Freixinho (Kragler) e Pedro Almendra (Murk) oferecem-nos duas interpretações consistentes não só no que diz respeito ao domínio do texto e da teatralidade da palavra como também da sua articulação com o corpo na exploração da intergestualidade. Com movimentos quase coreografados - recorde-se o esboço coreográfico de Pedro Almendra ao som de Je te veux, de Erik Satie -, os actores conseguem por vezes criar uma estilização que cobre a cadeia verbo-postura-mímica-gestualidade. "Um teatro que vai buscar tudo ao gestus", afirma Brecht, "não pode ignorar a coreografia. A elegância de um movimento e a graça de uma pose são suficientes para distanciar, e a invenção pantomímica ajuda muito a fábula" (Brecht 1978: 69). Personagens fundamentais nesta peça são ainda Babusch, o jornalista (Fernando Moreira), e o criado de mesa (Luis Araújo), que para além de comentarem a fábula vão assumindo cada vez mais a voz (que se intromete no discurso das personagens) e o gesto (da composição, da fragmentação, da montagem) do autor-rapsodo. Esta voz, que tem por função abrir o espectáculo ao público e reforçar a dimensão épica do texto ao mesmo tempo que organiza os diferentes transbordamentos - do

\section{$<>$ \\ $\checkmark$ \\ de Bertolt Brecht, enc. Nuno Carinhas, TNSJ, 2009 (< Pedro Frias, João Castro, Paulo Freixinho e Luis Araujo: > Sara Carinhas, Paulo Freixinho} e Pedro Frias: v Sara Carinhas e Paulo Freixinho), fot. João Tuna. 

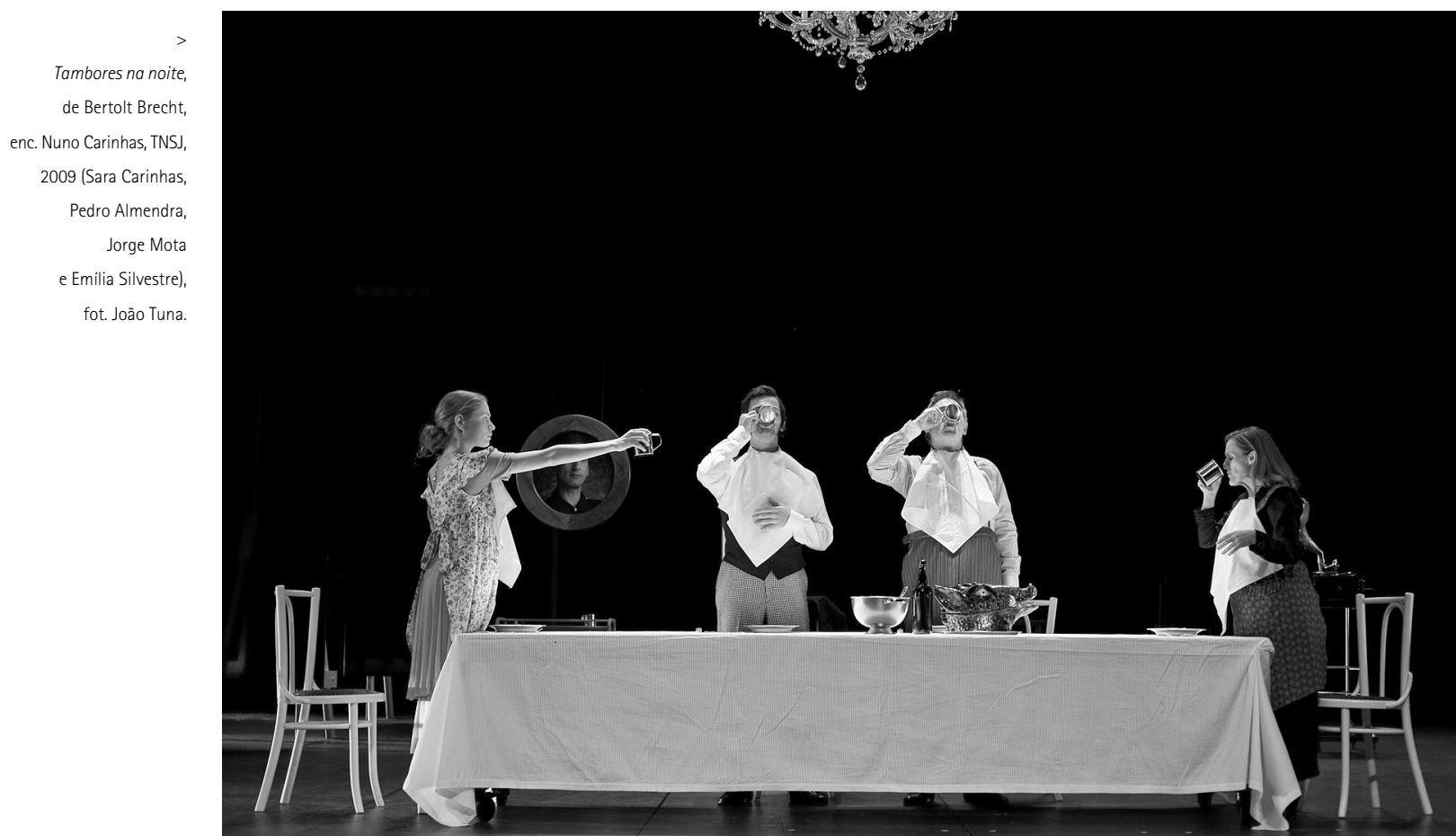

dramático (a relação interpessoal), do lírico (a expressão directa do eu) e do épico (a narrativa do mundo) - tem neste espectáculo um tratamento justissimo. Nuno Carinhas não hesita em colocar estas personagens face ao público, ou mesmo entre o público, explorando diversas formas de interpelação do espectador, levando-as inclusivamente a enunciar o texto didascálico onde a voz do autor-rapsodo também se faz ouvir. Como é evidente, o encenador poderia ter optado por uma solução mais "brechtiana", introduzindo apenas uma voz puramente épica (que observa o drama do exterior). Mas ao optar pela exploração desta "voz rapsódica", simultaneamente personagem que participa na acção e testemunha da acção, Nuno Carinhas dá-nos conta da importância desta multiplicação das vozes que faz explodir a forma puramente dramática, diversifica os pontos de vista sobre a fábula e organiza a sua montagem.

Das sintonias e/ou citações do universo brechtiano, destacaria ainda o desenho de luz de Rui Simão que evitou sempre as sombras confusas ou os contrastes violentos, os títulos dos actos em forma de legenda no canto superior esquerdo da boca de cena, a interpretação de Pedro Frias da song "A balada do soldado morto" e o uso da cortina a meia altura. De referir ainda a subtil e muito subterrânea convocação da pintura e da escultura (a lua vermelha inspirada nas esculturas de Kapoor, o cenário do primeiro acto onde Francisco Frazão viu uma citação das Meninas de Velásquez...), que nos fez rever a teoria brechtiana das "artes-irmãs" (Schwesterkünste): de acordo com o autor, "todas as artes-irmãs da arte dramática devem ser convidadas não para fabricar uma 'obra de arte total' à qual se entregariam e onde acabariam por se perder, mas para que, juntamente com a arte dramática, façam avançar a tarefa comum, cada uma à sua maneira, e em cuja relação procurarão distanciar-se mutuamente" (Brecht 1978: 69). Segundo Bernard Dort, por razões que se prendem com as inúmeras funções e ocupações do criador Brecht teria "sacrificado a independência destas 'artesirmãs' a uma concepção dramatúrgica unitária das obras que mostrava" (apud Sarrazac 2000: 70). Contudo, como refere ainda o crítico francês, a lição de Brecht vai mais longe do que a sua prática, e a sua obra constitui, ainda hoje, uma incontornável iniciação à "estética do descontínuo" (Sarrazac 2002: 56). E talvez seja exactamente isto que o espectáculo de Nuno Carinhas pretende mostrarnos: independentemente de todas as questões históricas e ideológicas, Brecht não é "um autor de ocasião"; é antes um "poeta desafiante", um inconformado que experimenta continuamente e que continuamente nos desconcerta.

"A lua vermelha", afirma Brecht, num passo reproduzido no Manual de Leitura deste espectáculo, "é o requisito quase imprescindivel - e muito perigoso - das revoluções". No entanto, é pelo branco da cama que Kragler acaba por optar, e a imagem final do espectáculo - uma imensa paisagem de carrinhos de bebé, os tais que vão substituir os cestos das munições no novo negócio dos Balick - quase nos faz esquecer o vermelho da lua. Não fora a voz rouca - lunar - de Tom Waits (Innocent when you dream), e tudo seria mais simples.

\section{Referências bibliográficas}

BRECHT, Bertolt (1978), Petit organon pour le théâtre, trad. Jean Tailleur, Paris, L'Arche.

CARINHAS, Nuno et al., (2009), "O efeito quinto", in Manual de Leitura de Tambores na noite, Porto, TNSJ, pp. 10-14

GUÉNOUN, Denis (2009), Livraison et délivrance: Théâtre, politique, philosophie, Paris, Belin.

PAVIS, Patrice (1996), L'analyse des spectacles, Paris, Dunod. SARRAZAC, Jean-Pierre (2000), Critique du théâtre, Belfor, Circé. --(2002), 0 futuro do drama, trad. Alexandra Moreira da Silva, Cadernos Dramat, Porto, Campo das Letras. 